Boletim IG. Instituto de Geociências, USP, V. 8: 55-66, 1977

\title{
ALGUMAS FEIÇÕES PERIGLACIAIS DO SUBGRUPO ITARARÉ (NEOPALEOZOICO), NO ESTADO DE SĀO PAULO
}

\author{
por \\ A. C. Rocha-Campos \\ A. R. Saad \\ P. R. dos Santos \\ e \\ M. E. C. B. de Oliveira \\ Departamento de Paleontologia e Estratigrafia
}

\begin{abstract}
Two superposed diamictites in the middle part of the Itarare Subgroup, cropping out along highway SP-280 in central-eastern São Paulo State, are separated by a boulder pavement associated with a disconformity at the top of the lower diamictite.

Wedge-shaped bodies up to 3 meters in height made up of sandstone, conglomeratic sandstone, and admixed sandstone and diamictite, taper downwards from the disconformity into the lower diamictite. Other channel-like bodies of sandstone occur at the top of or enveloped by the lower diamictite.

The former of these structures are interpreted as possible pseudomorphs or casts of ancient ice-wedges developed in frozen ground during the Gondwana glaciation. The latter probably include subglacial and surface channels eroded and filled by fluvio-glacial streams.

These features suggest the occurrence of a rigorous periglacial climate in this part of the Paraná Basin during the Late Paleozoic.
\end{abstract}

\section{RESUMO}

Dois diamictitos superpostos, da parte média do Subgrupo Itararé, aflorantes na rodovia SP-280, no Estado de São Paulo, estão separados por um pavimento de clastos, associado a uma discordância erosiva, no topo do diamictito inferior.

Corpos cuneiformes de arenito, arenito conglomerático e mistura de arenito e diamictito, de comprimentos variáveis, até cerca de 3 metros, estendem-se para baixo, a partir da superfície de discordância, penetrando no diamictito inferior. Outros corpos de arenito acanalados ocorrem envolvidos pelo diamictito inferior ou no seu topo.

As primeiras estruturas parecem corresponder a pseudomorfos de cunhas de gelo desenvolvidas em solo perenemente congelado (permafrost) durante a glaciação Gondvânica. As estruturas do segundo grupo incluem, provavelmente, canais subglaciais e superficiais, escavados por correntes flúvio-glaciais.

As feições descritas indicam a ocorrência pretérita de clima periglacial rigoroso nesta parte da Bacia do Paraná, durante o Neopaleozóico. 


\section{INTRODUÇÃO}

O exame da literatura sobre glaciações pré-pleistocênicas revela, somente, referências esparsas sobre a ocorrência de feições e depósitos característicos do ambiente periglacial.

O termo periglacial foi introduzido por W. Loziński, em 1909 (apud Washburne, 1973) para designar o clima e as feições controladas climaticamente, adjacentes às geleiras pleistocênicas. Autores subsequentes estenderam o significado do termo, no sentido de abranger todas as áreas nas quais a ação do congelamento ("frost") é um fator importante.

O reconhecimento de estruturas e depósitos de natureza periglacial seria, pois, de grande importância para a caracterização mais precisa de ambientes glaciais fósseis, à luz do modelo fornecido pela glaciação cenozóica. Tal investigação é, contudo, dificultada, em grande parte, pelos problemas de preservação de feiçð̄es periglaciais diagnósticas no registro geológico e, ainda, no que tange à sua discriminação daquelas formadas por processos sedimentares diversos (Washburne, 1973).

No caso particular da glaciação Gondvânica, conhecem-se algumas estruturas associadas aos diamictitos que poderiam decorrer de processos característicos do ambiente periglacial. Podem ser citados como exemplos, corpos cuneiformes de arenitos intercalados em diamictitos do Subgrupo Itararé interpretados como pseudomorfos de cunhas de gelo, ou preenchimento de antigas crevasses (Washburne, 1930; Frakes et al., 1968). Rocha-Campos (1966) e Rocha-Campos et al. (1968) descreveram lentes, veios e camadas de arenito e conglomerado, de milímetros a decímetros de espessura, de disposição variada, simples ou ramificados, às vezes complexamente, circunscrevendo fragmentos da litologia encaixante (geralmente diamictito), que se assemelham, geometricamente, de maneira notável, a veios, lentes e camadas de gelo e seus pseudomorfos, que ocorrem em depósitos glaciais recentes e pleistocênicos (Taber, 1929; Schafer, 1949; Hamelin \& Cook .
1967; Washburne, 1973). Em alguns casos, a ausência de solo fóssil associado a essas estruturas tem dificultado a sua interpretação correta (Frakes et al., 1969), porém feições periglaciais características podem se formar, também, em sedimentos correspondentes a "drift" estratificado (Péwé et al., 1969).

Vale ainda mencionar, que o termo periglacial tem sido também, inadequadamente, usado na literatura nacional para designar sedimentos, provavelmente flúvio-glaciais, intercalados entre os diamictitos do Subgrupo Itararé (e.g. Bigarella \& Salamuni, 1967).

O objetivo da presente nota é descrever e discutir a provável origem periglacial (s.s.) de estruturas que ocorrem incluídas em um diamictito neopaleozóico da parte média do Subgrupo Itararé (Grupo Tubarão), na parte nordeste da Bacia do Paraná. As mais comuns, nesta localidade, são corpos cuneiformes de arenito, arenito conglomerático ou mistura de arenito e diamictito, involucrados por diamictito, que se assemelham a cunhas de gelo fósseis ou, ainda, a preenchimentos de fraturas de congelamento sazonal. Outros corpos arenosos, sob forma de lentes de arenito ou arenito conglomerático são interpretados como preenchimento de canais subglaciais ou superficiais escavados e preenchidos por correntes flúvio-glaciais.

A ocorrência de tais estruturas implica na existência pretérita de sedimentos sazonal ou perenemente congelados (permafrost) em ambiente periglacial, adjacente às geleiras neopaleozóicas, no nordeste da Bacia do Paraná.

\section{LOCALIZAÇÃO E ESTRATIGRAFIA}

As estruturas descritas ocorrem na parte média da sequência sedimentar do Subgrupo Itararé (Grupo Tubarão) aflorante em dois cortes paralelos da rodovia SP-280 (Rodovia Castelo Branco, pista de retorno), cerca de $100 \mathrm{~m}$ antes do $\mathrm{km} \mathrm{111,} \mathrm{na} \mathrm{regiáo} \mathrm{centro-}$ -leste do Estado de São Paulo. 


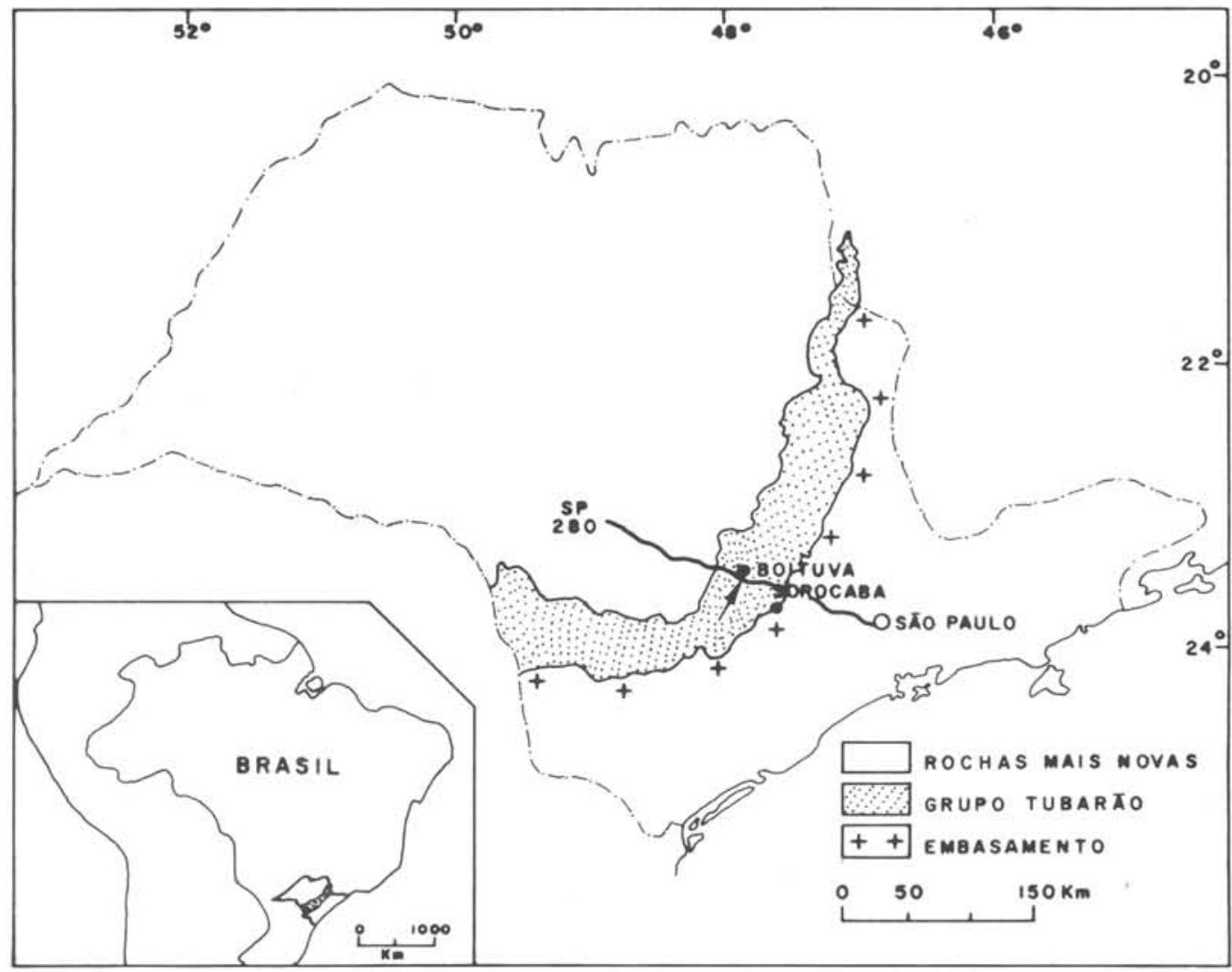

Fig. 1 - Localização das feições descritas no Estado de São Paulo

Neste local, dois diamictitos, de cerca de 4 metros de espessura máxima exposta, superpõem-se, separados por uma discordância erosiva, ao longo da qual ocorre um alinhamento de clastos de tamanho e natureza variada, pertencentes ao topo do diamictito inferior. $\mathrm{O}$ alinhamento de clastos corresponde, provavelmente, à seção vertical de um pavimento de clastos do tipo intertill, cuja descrição mais pormenorizada deverá constar de artigo subsequente a este (Fig. 2).

$\mathrm{O}$ diamictito inferior, de matriz silto-argilosa, é megascopicamente maciço, exceto pela presença, em algumas regiões, particularmente, junto aos corpos cuneiformes, de superfícies de físsilidade inclinadas e horizontais. O diamictito superior difere do primeiro pela sua matriz arenosa e por conter maior número de clastos dispersos.

\section{ESTRUTURAS CUNEIFORMES}

As estruturas cuneiformes (figs. 2-6) estreitam-se para baixo, sub-verticalmente, ou obliquamente, variando de comprimento exposto no corte vertical, desde 1,60 até 3 metros. Suas expessuras variam, no geral, de cerca de $1 \mathrm{~m}$, até poucos centímetros (estruturas $\mathrm{A}$, B. C. e E); a maior delas (D), tem cerca de $5 \mathrm{~m}$ de expessura.

Suas dimensões e forma no plano horizontal não puderam ser determinadas. Correspondem, aparentemente, a corpos grosseiramente tubulares, ou prismáticos, normalmente encurvados ou ondulados ao longo de seu comprimento e dispostos obliquamente em relação ao plano do corte da estrada, segundo, aproximadamente, SW-NE (N 42o - 579) e leste-oeste (N 770 - N829). Todas as cinco estruturas estudadas estão truncadas em sua porção superior pela superfície de discordância que separa os dois diamictitos.

Os contatos laterais entre os corpos cuneiformes e o diamictito envolvente são bruscos e ondulares incluindo expansões e constrições, particularmente nas extremida- 


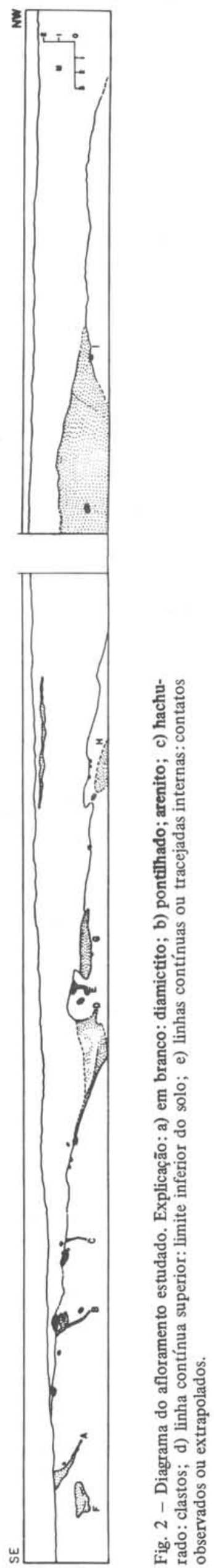


des basais dos corpos, que normalmente exibem entumescimentos, em alguns casos associados a zonas limonitizadas (estruturas B e C).

Três das estruturas estudadas (A, C e D) são simples; a estrutura B parece ligada, lateralmente, a um corpo grosseiramente elíptico de arenito conglomerático incluído dentro do mesmo diamictito. A estrutura E apresenta, no seu topo, diversos ramos de formas e dimensões variadas.
O material de preenchimento de quatro das estruturas (A, B, C e E) é semelhante e contituído de arenito fino a médio, às vezes conglomerático, particularmente, na porção superior dos corpos (estruturas A e B). Em três casos mostram evidências de estratificação subhorizontal, plana ou ligeiramente encurvada. A estrutura D é constituída de mistura complexa de arenito semelhante ao que preenche as outras estruturas e diamictito. Nas proximidades das estruturas

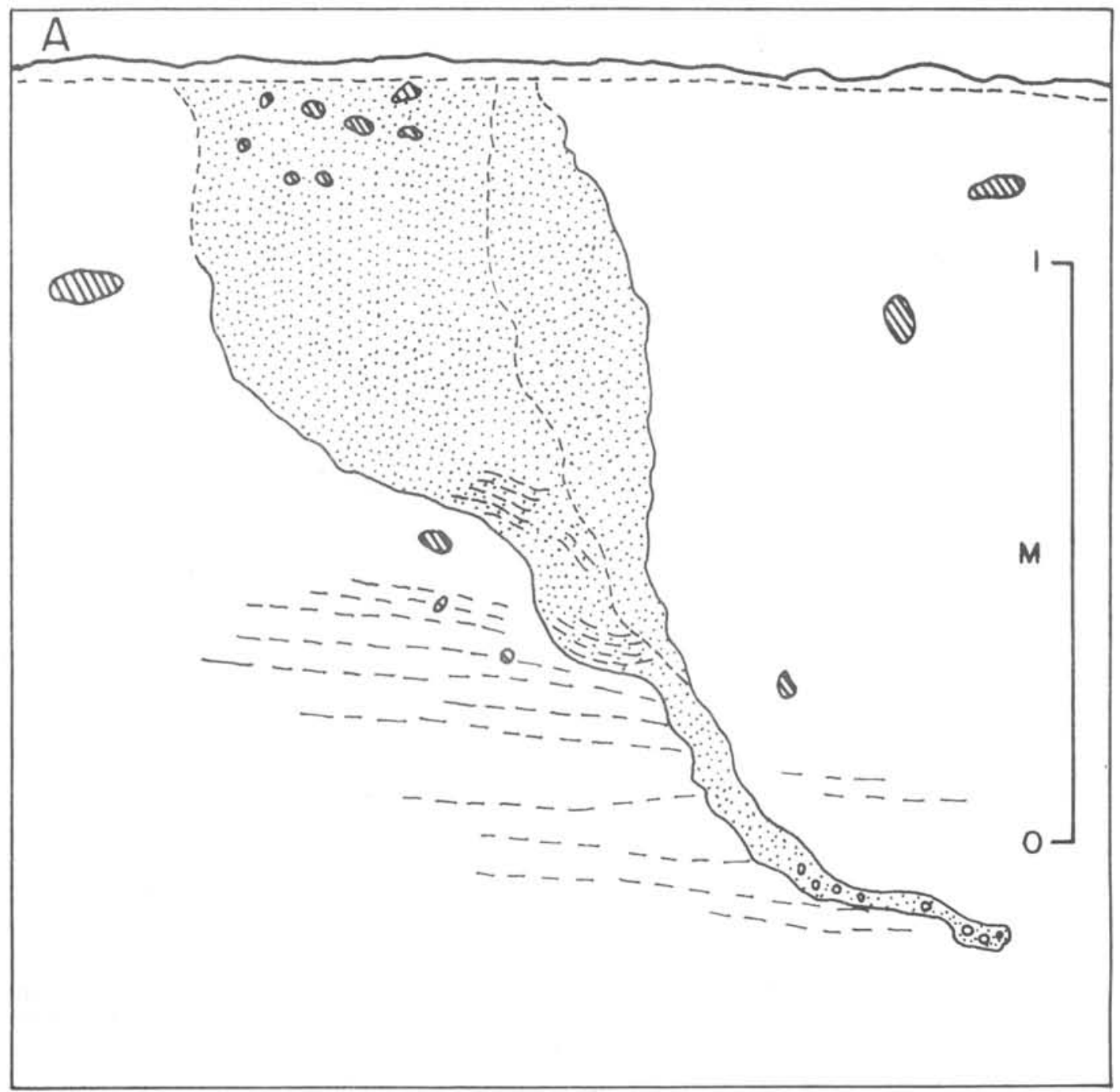

Fig. 3 - Estrutura cuneiforme A, (ver localização no diayrama da fig. 2): a) linha tracejada: superfície de fissilidade do diamictito e estratificaçōes do arenito; b) pontilhado denso: zonas limonitizadas. Outras legendas iguais às da Fig. 2 . 


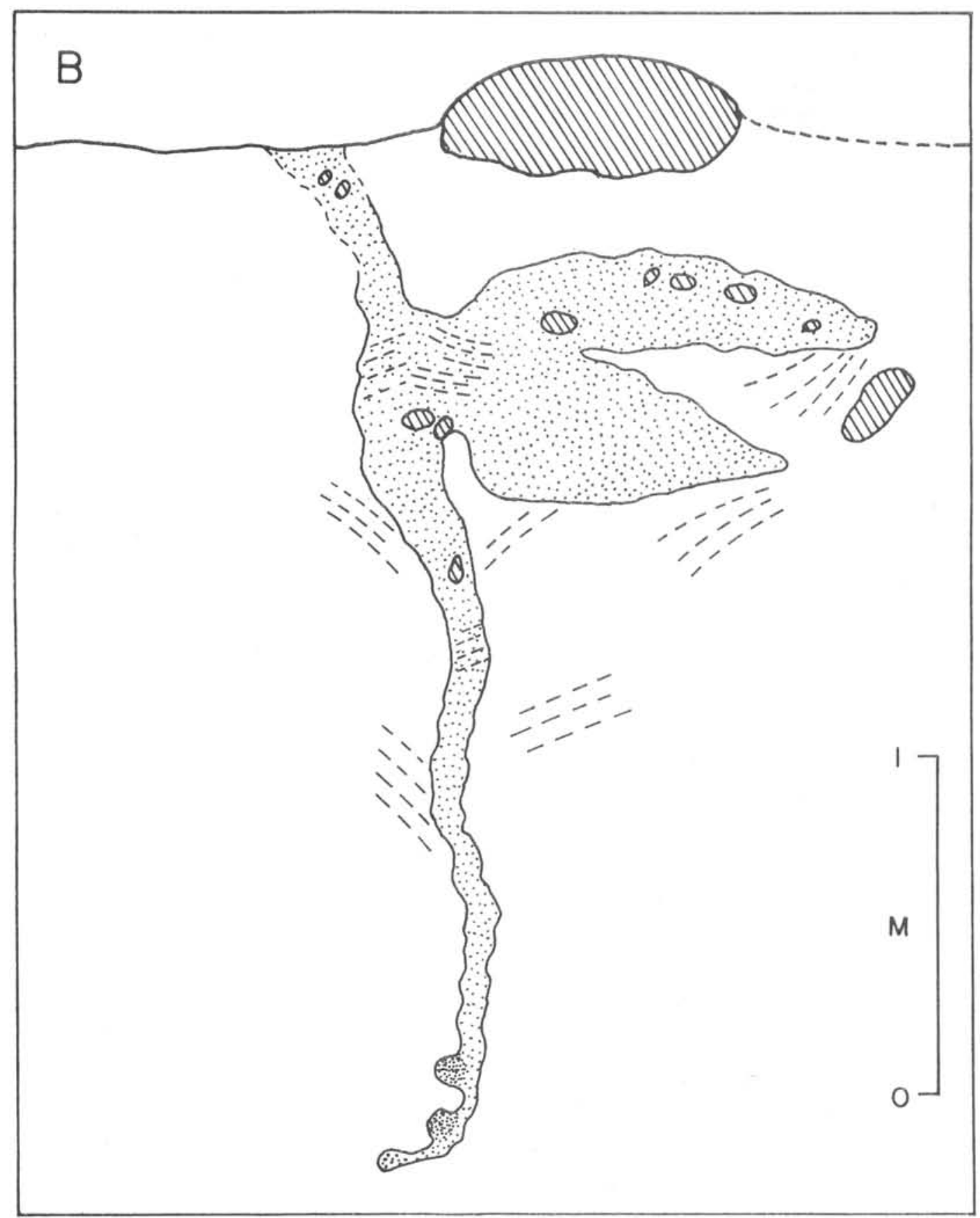

Fig. 4 - Estrutura cuneiforme B, (ver localização no diagrama da fig. 2): a) linha tracejada: superfície de fissilidade do diamictito e estratificaçōes do arenito; b) pontilhado denso: zonas limonitizadas. Outras legendas iguais às da Fig. 2.

$\mathrm{A}, \mathrm{B}, \mathrm{C}$ e $\mathrm{E}$ o diamictito inferior, que circuncreve os corpos, no geral, megascopicamente maciço, desagrega-se em lâminas irre- gulares, subhorizontais, planas ou ligeiramente inclinadas ou encurvadas para cima ou para baixo. 


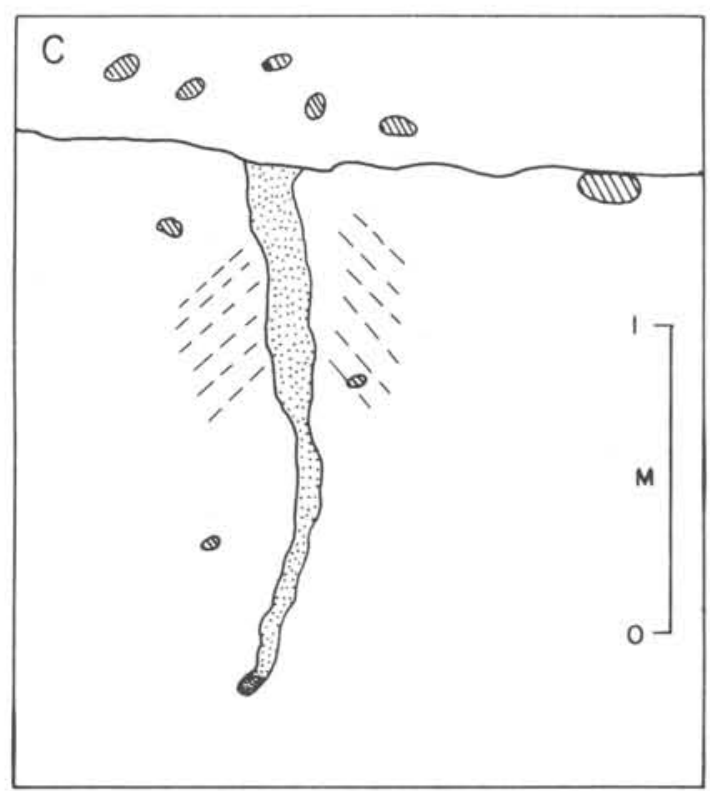

Fig. 5 - Estrutura cuneiforme C, (ver localizaçâo no diagrama da fig. 2): a) linha tracejada: superfície de fissilidade do diamictito e estratificações do arenito; b) pontilhado denso: zonas limonitizadas. Outras legendas iguais às da Fig.2.

\section{OUTRAS ESTRUTURAS ASSOCIADAS}

$\mathrm{Na}$ mesma localidade ocorrem, ainda, corpos lenticulares de arenito ou arenito conglomerático de contatos brusco, completamente envolvidos pelo diamictito inferior (estruturas $\mathrm{F}$ e $\mathrm{H}$ ), ou aprofundando-se neste a partir do seu topo (estruturas G e I). Sua forma, estrutura interna e natureza do seu contato com o diamictito envolvente permitem identificá-las como estruturas acanaladas. Seus comprimentos variam de 2 a $15 \mathrm{~m}$

A estrutura $F$ apresenta-se, grosseiramente, triangular em seção, de topo plano e base convexa. É constituída de arenito fino, bem selecionado e exibe evidências de estratificação interna encurvada, paralelamente à sua base. A estrutura $\mathrm{H}$, aparentemente similar, está mal exposta e suas características internas não puderam ser examinadas.

As estruturas G e I intercalam-se, parcialmente, no diamictito inferior, sendo reco-

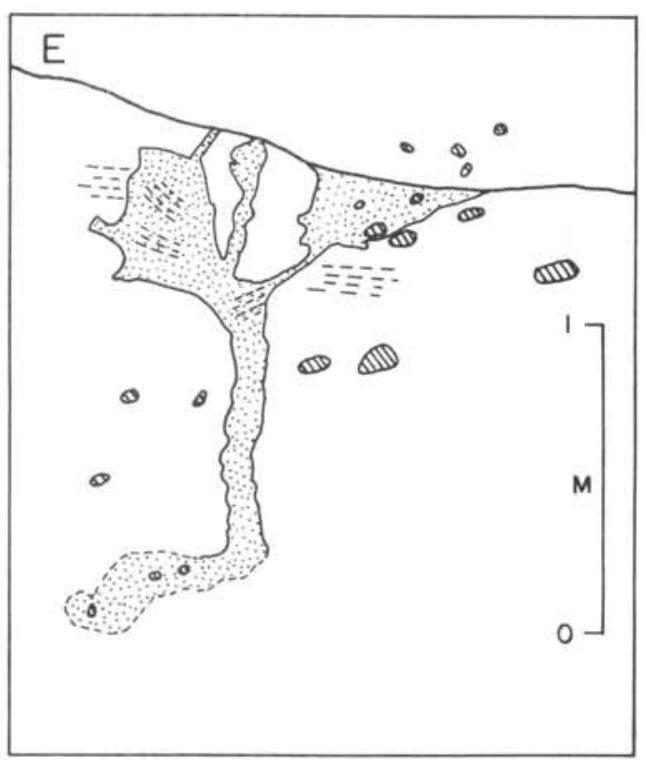

Fig. 6 - Estrutura cuneiforme E, (ver localização no diagrama da fig. 2): a) linha tracejada: superfície de fissilidade do diamictito e estratificações do arenito; b) pontilhado denso: zonas limonitizadas. Outras legendas iguais às da Fig. 2.

bertas pelo diamictito superior, do qual também se separam por superfície de contato brusco. A estrutura I, a maior delas, parcialmente exposta, exibe uma gradação do material que a preenche, passando de arenito conglomerático, junto à base, até arenito fino na sua porção superior.

\section{ORIGEM}

A associação das estruturas acima descritas e diamictitos do Subgrupo Itararé, cuja origem glacial já está inequivocamente estabelecida (Leinz, 1937; Martin, 1961; Rocha-Campos, 1967; Frakes \& Crowell, 1969; etc.), implica na possibilidade de explicar a sua formação através de processos em operação nesse ambiente.

No que diz respeito às estruturas cuneiformes, as quatro hipóteses possíveis de gênese envolveriam sua identificação como: a) diques clásticos; b) preenchimentos de fraturas 
de dessecamento; c) preenchimentos de fraturas de contração termal ("thermal contraction-cracks", Péwé et al., 1969); e d) preenchimentos de crevasses (Flint, 1928; Osborne, 1950).

A interpretação dos corpos cuneiformes como diques clásticos não encontra apoio nas evidências de campo disponíveis.

As estruturas distribuem-se, espacialmente, de maneira regular e apresentam evidentes sinais de erosão ao longo de suas margens. Contém, ainda, estratificação perpendicular às paredes e não paralela, como parece ocorrer em diques clásticos (Harms, 1965; Peterson, 1966).

As estruturas assemelham-se, morfologicamente, também, e têm dimensōes próximas, a de fendas de dessecamento de grande porte (Tomkins, 1965; Neal \& Mott, 1967). Estas, contudo, estão normalmente associadas a sedimentos de granulação fina como, por exemplo, siltes e argilas lacustrinas ou de playas. Não há, também, no Subgrupo Itararé, evidências paleoclimáticas compatíveis com o dessecamento intenso que deveria ter afetado o antigo diamicto para fendilhá-lo.

Os corpos cuneiformes poderiam, ainda, representar fraturas de contração termal "fósseis", i. e., preenchimentos de fraturas de congelamento sazonal, pseudomorfos de cunhas de gelo, ou cunhas de areia. Tais tipos de estruturas são caracteríticas do ambiente periglacial.

As fraturas de congelamento sazonal (Péwé et al., 1969) decorrem de contração termal do solo congelado, durante sucessivos invernos, posteriormente preenchidas por areias ou argilas transportadas por água, acrescidas de material desabado das paredes, por ocasião dos degelos primaverís. A repetição desse processo, durante um longo tempo, causa o crescimento das fendas, que se propagam para baixo, podendo sofrer deflexões em decorrência de variações texturais do sedimento envolvente, interferência de clastos, etc. A ação das águas de degelo resultaria na erosão das paredes e alargamento das antigas fendas levando à modificação de suas formas originais.

Estruturas extremamente semelhantes originar-se-iam por substituição de cunhas de gelo formadas por sucessivos incrementos, dentro de fraturas abertas por contração térmica em solo perenemente congelado (permafrost), durante períodos extremamente frios do inverno em que a temperatura atinge -150 a $-200 \mathrm{C}$. As fases de congelamento alternam-se com épocas de degelo primaveril, quando ocorre preenchimento das fraturas por água, posteriormente congelada. Esta alternância de contração e expansão resulta no encurvamento para cima dos estratos dos sedimentos afetados, junto às cunhas (Lachenbruch, 1960; Péwé et al., 1969; Péwé, 1973, Fig. 33). Variações nas características texturais dos sedimentos envolventes podem, também, causar encurvamentos e flexões das fraturas, posteriormente, alargadas, irregularmente, por erosão das águas de degelo e abatimento das paredes. A posterior substituição do gelo por sedimentos, após fusão das cunhas, resulta no colapso do material encaixante adjacente, que pode mostrar, então, estratificação encurvada para baixo e mesmo perturbações variadas (Lachenbruch, 1960; Péwé et al., 1969; Péwé, 1973).

Cunhas de areia ("sand-wedges", Péwé, 1959; Péwé et al., 1969), por sua vez, resultam também de fraturamento por contração termal de permafrost, mas o seu preenchimento é contituído de areias eólicas. Formam-se, normalmente, em áreas extremamente áridas e sem vegetação, nas quais a água de degelo é rara e material congelado ("hoar-frost") não se acumula nas fraturas durante o inverno (Péwé, 1959; Péwé et al., 1969).

A natureza do material que constitue, atualmente, as estruturas cuneiformes estudadas (arenito, arenito conglomerático e/ou diamictito) permite excluir, de imediato, a última alternativa de origem.

Com relação às duas primeiras, as características morfológicas de seus exemplares "fósseis" são muito próximas entre si e coincidem, em grande parte, com as das estruturas cuneiformes estudadas. 
Fraturas de congelamento sazonal ocorrem, atualmente, no Alaska, em áreas sem vegetação e desprovidas de cobertura de neve durante $o$ inverno. Tais condições permitem um resfriamento rápido e intenso do solo, quando a temperatura atmosférica atinge 40 a a -50 C (Péwé et al., 1969, Péwé, 1973). No presente caso, não há evidências para se determinar se essas circunstâncias existiram no Neopaleozóico, na área de ocorrência das estruturas.

Uma característica que poderia, talvez, servir para distinguir entre os dois tipos de fraturas de contração termal, deriva dos processos de substituição ou pseudomorfose das cunhas de gelo, conforme já discutido, que resultam no encurvamento para cima de sedimentos estratificados, junto às estruturas, $\mathrm{e}$ mesmo, na produção de perturbações mais complexas do acamamento. O material que circuncreve as estruturas aqui descritas consiste de diamictito, essencialmente maciço, pelo menos, megascopicamente e, portanto, eventuais perturbações estruturais poderiam não ser visíveis. Nota-se, contudo, junto a algumas estruturas estudadas, ligeiro encurvamento de possíveis superfícies de fissilidade do diamictito, que se assemelham às deformações resultantes de processos de pseudomorfose de cunhas de gelo (Péwé et al., 1969). Estas formam-se, normalmente, em "drift" estratificado e solo, mas não conhecidos exemplos desenvolvidos em sedimentos grosseiros, conglomeráticos (areias e cascalhos flúvio-glaciais, Péwé et al., 1969; Péwé, 1973)., Poderiam, portanto, também, ocorrer em substrato formado de "drift" não estratificado, ou till congelado, como seria o caso das estruturas aqui descritas.

A natureza do material que constitue, atualmente, as estruturas cuneiformes e a estratificação interna, perpendicular às paredes, observada em algưmas delas, são consistentes com a interpretação adotada. Representariam sedimentos transportados por águas de degelo, misturados com materiais desabados das paredes das fraturas, em decorrência da perda de apoio.

Restaria, finalmente, examinar a pos- sibilidade das estruturas aqui descritas correspenderem a preenchimentos de crevasses ("crevasse fillings", Flint, 1928). Frakes et al. (1968) descreveram estruturas cuneiformes similares, no geral, às aqui tratadas, porém ligadas a camadas de arenito intercaladas em diamictito do Subgrupo Itararé, junto a Gramadinho, Estado de São Paulo, identificando-as como prováveis preenchimentos de fissuras abertas em antigo till congelado, propagadas a partir de crevasses formadas em geleiras superjacentes. As características gerais dos preenchimentos de crevasses sumarizadas por Flint (1928) e Osborne (1950) aproximam-nos dos eskers, com os quais têm sido, provavelmente, confundidos. Sua estrutura e tamanho separam-nos, contudo, das feições aqui descritas.

Quanto aos corpos arenosos lenticulares, sua geometria aparente, estruturas internas e relações de contato parecem indicar tratarem-se, realmente, de preenchimentos de canais subglaciais ou superficiais escavados dentro e sobre $\mathrm{o}$ antigo diamicto por ação de águas correntes, provavelmente ligadas a fases de degelo $\mathrm{e}$ pseudomorfose das cunhas de gelo. A similaridade do material que constitue os dois grupos de estruturas é consistente com essa interpretação.

A ocorrência das estruturas cuneiformes e sua possível correspondência a pseudomorfos de cunhas de gelo (ou, alternativamente, a fraturas de congelamento sanzonal), tem importantes consequências no entendimento do paleoclima da Bacia do Paraná. Ambos os tipos de estruturas são características do ambiente periglacial e decorrem de severas condições de temperatura que afetam o substrato de regiôes glaciadas.

Cunhas de gelo e os padrões poligonais do substrato a elas associadas constituem uma feição característica do solo perenemente congelado, ou permafrost. De acôrdo com sugestão de Lachenbruch (in Péwé et al., 1969), o fraturamento do permafrost e formação das cunhas de gelo ocorrem a temperaturas de cerca de -150 a a $-209 \mathrm{C}$, durante o inverno, em áreas adjacentes às calotas glaciais, a distâncias variáveis destas de 50 - 
100 km (Péwé, 1973), sujeitas a clima rigoroso, em ambiente periglacial. A degradação e substituição do gelo decorrem de melhoria climática, que pode ser brusca ou gradativa, levando ao desaparecimento total das cunhas de gelo, ou ao seu degelo seletivo, juntamente, ao do permafrost. Em ambos os casos, portanto, a temperatura local deve elevar-se e manter-se, durante certo tempo,a $00^{\circ} \mathrm{C}$, ou pouco mais(Péwé et al., 1969; Péwé, 1973). A correspondência das estruturas cuneiformes a cunhas de gelo fósseis implicaria, pois, na ocorrência dessa sucessão de eventos, durante o Neopaleozóico, na parte norte da Bacia do Paraná.

$\mathrm{Se}$, alternativamente, as estruturas cuneiformes aqui descritas, representarem preenchimentos de fendas de contração sazonal, elas evidenciariam que $o$ substrato periglacial da região teria sido, provavelmente, desprovido de cobertura vegetal e neve e submetido a temperaturas ainda mais rigorosas, de cerca de -20 ọ a -50 C. A evolução posterior das fendas de contração sazonal, contudo, não envolve, necessariamente, a melhoria climática que é inerente à formação dos pseudomorfos de cunhas de gelo.
As outras estruturas ocorrentes no afloramento estudado, interpretadas como canais subglaciais ou superficiais, são compatíveis com as características ambientais acima esboçadas e resultariam, provavelmente, do degelo posterior, associado à melhoria climática sazonal ou, mais provavelmente, de maior duração, concomitantemente a pseudomorfose das cunhas de gelo.

A erosão superficial decorrente do fluxo de correntes flúvio-glaciais responsáveis pelo aporte e deposição de material arenoso e conglomerático, poderia ter provocado a formação de um concentrado de clastos ("lag concentrate") sobre o till inferior, posteriormente retrabalhado sob a forma de pavimento, pela reativação da ação glacial responsável pela deposição do till superior.

Agradecimentos: A presente nota é uma contribuição do Projeto PICG Paleozóico Superior da América do Sul (Proj. nọ 42), subvencionado pelo $\mathrm{CNPq}$ (Proc. n.? 2222.0219/75).

\section{BIBLIOGRAFIA}

BIGARELLA, J. J. \& SALAMUNI, R. - 1967 - Some palaeogeographic and palaeotectonic features of the Parand Basin. In J. J. Bigarella, R. D. Becker e I. D. Pinto (Eds.), Problems in Brazilian Gondwana Geology: 235-301, Curitiba.

FLINT, R. F. - 1928 - Eskers and crevasse fillings. Amer. Jour. Sci, $5^{\text {th }}$ ser., $_{\text {. }} 15$ (89): 410-415.

FRAKES, L. A. \& CROWELL, J. C. - 1969 - Late Paleozoic glaciation :I. South America. Bull. Geol. Soc. Amer., 80 (1): $1007-1042$.

FRAKES, L. A.,FIGUEIREDO FILHO, P. M. DE \&FULFARO, V. J. - 1968 - Possible fossil eskers and associated features from the Parand Basin, Brazil. Jour Sed. Petr., 38 (1) : 4-12.

HAMELIN, L. E. \& COOK, F. A. - 1967 - Le periglaciaire par l'image. Illustrated glossary of periglacial phenomena. Les Presses de l'Université Laval, Québec.

HARMS, J. C. - 1965 - Sandstone dikes in relation to Laramide faults and stress distribution in the southern Front Ranges Colorado Bull. Geol. Soc. Amer., 76: 981-1002.

LACHENBRUCH, A. H. - 1960 - Thermal contraction cracks and ice wedges in permafrost. U. S. Geol. Surv. Research, Short Papers in Geol. Sci : B404-406.

LEINZ, V. - 1937 - Estudos sobre a glaciação permo-carboniffera do Sul do Brasil. Dep. Nac. Prod. Miner, Div. Fom. Prod. Miner., Bol. 21. 
MARTIN, H. - 1961 - The hypothesis of continental drift in the light of recent advances of geological knowledge in Brazil and in South West Africa. Geol. Soc. South Africa, Ann., 64, Alex L. du Toit Mem. Lectures, 7.

NEAL, J. T. \& MOTT, W. S. - 1967 - Recent geomorphic changes in playas of Western United States. Jour. Geole, 75 (5) : 511-525.

ORBORNE, F. F. - 1950 - Marine crevasse fillings in the Lotbnière region, Québec, Amer. Jour. Sci., 248 (12) : 874-890.

PETERSON, G. L. - 1966 - Structural interpretation of sandstone dikes, North Sacramento Valley, California. Bull, Geol. Soc. Amer., 77 (8) : 833-842.

PÊWE, T. L. - 1959 - Sand-wedge polygons (tesselations) in the McMurdo Sound region, Antarctica - a progress report. Amer. Jour. Sci., 257 (8) : 545-552.

PEWE, T. L. - 1973 - Ice wedge casts and past permafrost distribution in North America. Geoforum, 15/73: 15-26.

PEWE, T. L., CHURCH, R. E. \& ANDRESEN, M. J. - 1969 - Origin and paleoclimatic significance of large scale polygons in the Donnely Dome area, Alaska. Spec. Pap. Geol. Soc. Amer., 109.

TABER, S. - 1929 - Perennially frozen ground in Alaska. Bull. Geol. Soc. Amer., 54 (10) : 1433-1548.

TOMKINS, J. Q. - 1966 - Polygonal sandstone features in Boundary Butter anticline area, San Juan County, Utah: reply. Bull. Geol. Soc. Amer., 77 (11) : 1331-1332.

ROCHA-CAMPOS, A. C., YOSHIDA, R. \& FARJALLAT, J. E. S. - 1968 - New glacial features of the Upper Paleozoic Itararé Subgroup in the State of São Paulo, Brazil. Bol. Sơc. Bras, Geole, 17 (1) : 47-57.

ROCHA-CAMPOS, A. C. - 1966 - Novas ocorrências de fósseis marinhos no Grupo Tubarão em São Paulo e Santa Catarina. Bol. Soc. Bras. Geol., 15 (4) : 5-13.

ROCHA-CAMPOS, A. C. - 1967 - The Tubarão Group in the Brazilian portion of the Parand Basin. In J. J. Bigarella, R. D. Becker e I. D. Pinto (Eds), Problems in Brazilian Gondwana Geology : 27-102, Curitiba.

SCHAFER, J. P. - 1949 - Some periglacial features in Central Montana. Jour. Geol., 57 (2) : 154-174.

WASHBURNE, C. W. - 1930 - Petroleum geology of the State of São Paulo. Bol. Com. Geogr. São Paulo, 22.

WASHBURNE, A. L. - 1973 - Periglacial processes and environments. Edward Arnold, London. 